\title{
VR technologies as an extension to the museum exhibition: A case study of the Silk Road museums in Samarkand
}

\author{
Kamil Żyła - Jerzy Montusiewicz - Stanisław Skulimowski - Rahim Kayumov
}

Kamil Żyła, PhD Eng

Lublin University of Technology - Department of Computer Science

Nadbystrzycka 36B, 20-618 Lublin

Republic of Poland

e-mail:k.zyla@pollub.pl

Jerzy Montusiewicz, DSc Eng

Lublin University of Technology - Department of Computer Science

Nadbystrzycka 36B, 20-618 Lublin

Republic of Poland

e-mail: j.montusiewicz@pollub.pl

Stanisław Skulimowski, MSc Eng

Lublin University of Technology - Department of Computer Science

Nadbystrzycka 36B, 20-618 Lublin

Republic of Poland

e-mail: s.skulimowski@pollub.pl

Rahim Kayumov, MSc

Samarkand State University - Scientific-Experimental Museum-Laboratory

University Boulevard 15, 703004 Samarkand

Republic of Uzbekistan

e-mail: rahim-kayumov@rambler.ru

Mureológia a kulturne dedičstvo, 2020, 8:4:73-93

DOI: $10.46284 / \mathrm{mkd} .2020 .8 .4 .6$

$V R$ technologies as an extension to the museum exhibition: $A$ case study of the Silk Road museums in Samarkand

The geographical dispersion of the Silk Road generates a number of problems with the availability of its heritage for visitors. ICT can at least partially address these problems. This article discusses the concept of extending the Silk Road museums' offer with virtual reality (VR) technologies, which has been tested based on a virtual exhibition, developed through a long-term cooperation between Lublin University of Technology and museums in Samarkand in the field of 3D digitization and dissemination of their exhibitions. A survey of a group of spectators was conducted and its results are discussed. It revealed that VR is a promising technology, widely accepted among spectators and well suited for the specificity of the Silk Road museums, and it could be used primarily to complement traditional exhibitions.

Keywords: museum, virtual reality, virtual museum exhibitions, Silk Road, exploratory survey

\section{Introduction}

The classic approach to organizing museum exhibitions requires the visitor to physically visit different and often distant locations. In addition, it is troublesome for the visitor to assess (for example, based only on photographs, documents and other information published on a website) the extent to which the exhibition will be of interest to him/her. Finally, the greater the geographical dispersion the more time is needed for sightseeing; furthermore, the visitor may need to obtain appropriate travel documents and permits, and greater travel 
K. Żyła - J. Montusiewicz - S. Skulimowski - R. Kayumov: VR technologies...

and accommodation costs will be incurred, not to mention difficulties affecting people with disabilities. In some cases, interesting exhibits cannot be seen due to political instability or ongoing military operations. Recent unexpected events - namely, the global coronavirus pandemic, which has caused border closures and restrictions on travel and tourism, as well as the closure of cultural institutions such as museums - show the importance of digitising museum artefacts and making them available online.

The above-mentioned issues are particularly related to the heritage of the Silk Road, which is scattered over thousands of kilometres between culturally different countries (from China, through the Muslim countries of Central Asia and the Middle East, to Christian Armenia). Therefore, the idea of extending the offer of the Silk Road museums' exhibitions with elements utilising ICT techniques, and facilitating remote access to these resources, seems like an obvious, good and even desired solution. One technology that could be suitable for such purposes is virtual reality (VR), which enables museums to build virtual exhibitions presenting digital representations of real objects and their 3D surroundings, where a person is put into a state of immersion by means of a specialised headset. The viewer can behave as if in museum, walking around the presented heritage artefacts, reading a story or watching audiovisual content concerning a particular object, moving his/her head to change the perspective, travelling around a replica of the museum's rooms and corridors, and so on. Nevertheless, it has to be acknowledged here: it seems - and this was confirmed by our own research - that the desire to physically visit the museum, to soak up its atmosphere and so on, will not be eliminated for a long time.

Now let us consider some of arguments that make virtual exhibitions utilising VR technologies an interesting solution. First, a potential visitor can have a bit of fun while becoming, to a significant degree, familiar with a museum's offer, without physically visiting it. Second, the technical barriers are not high. It is easy to get affordable devices offering sufficient performance that would enable people to watch virtual exhibitions, even at home using their personal smartphones. Third, initiatives such as the European Year of Cultural Heritage, ${ }^{1}$ Work Plan for Culture 2019-2022 $2^{2}$ and the United Nations Development Programme (Standard 4: Cultural Heritage ${ }^{3}$ ) as well as other initiatives run by local governments, stress the importance of sustaining the legacy of cultural and natural heritage and protecting it from destruction by human or natural forces. These initiatives have made it easier for museums to obtain funding to digitise their resources and present them in novel ways. Thanks to this, an ever-wider range of professional and amateur equipment for digitising and visualising resources in the 3D environment (in such a way that preserves not only the geometry and dimensions of a digitised object, but makes it photorealistic) is becoming widely available, with the indirect effect that it is also becoming cheaper. At last we are witnessing a generational shift toward an information society; a change that cannot be ignored. The use of VR technologies can be considered a part of the reconceptualisation of museum exhibitions targeting the upcoming Generation $Z^{4}$

\footnotetext{
${ }^{1}$ European Year of Cultural Heritage, accessed 22 January 2020, https://europa.eu/cultural-heritage/european-year-cultural-heritage_en.html

${ }^{2}$ Europa Nostra, Work plan for culture 2019-2022, accessed 22 January 2020, https://www.europanostra.org/workplan-for-culture-2019-2022-eu-ministers-of-culture-make-the-legacy-of-the-european-year-a-priority/

${ }^{3}$ UNDP, Social and Environmental Standards, Standard 4, accessed 22 January 2020, https://info.undp.org/sites/bpps/ SES_Toolkit/SitePages/Standard\%204.aspx

${ }^{4}$ PRIPORAS, Constantinos-Vasilios et al. Generation Z consumers' expectations of interactions in smart retailing: A future agenda. In: Computers in Human Behavior, vol. 77, 2017, p. 374-381.
} 
(people born after 1995), characterised by being heavy users of technology and a generation who have never known the world without the Internet.

As we can see there are no significant technological barriers, but there are many factors that encourage the use of VR by museums. However, the main question is whether the cultural heritage community is willing to accept the idea of exhibitions in virtual reality and if so, in what capacity: as complementary content, or even as a replacement for traditional exhibitions that can be viewed on site at the museum? To investigate this, we have drawn upon a longterm collaboration between Lublin University of Technology and the Silk Road museums in Samarkand ${ }^{5}$ to carry out exploratory research. Another motivation for choosing the Silk Road as a case study is the pioneering commitment of Lublin University of Technology in this region.

For the purpose of our research we prepared a virtual exhibition presenting digital copies of real objects owned by these museums. The objects were $3 \mathrm{D}$ scanned on site and transformed into precise 3D models by employees of Lublin University of Technology. In the course of collecting research material, we conducted person-to-person interviews ${ }^{6}$ with museum professionals from regions connected by the Silk Road about the use of advanced ICT, including virtual reality, to improve the scope and availability of services covered by the museums. Another part of our research involved a survey of young adults belonging to Generation Z (born between 1995 and 2001) from Eurasia interested in heritage and innovative methods of presenting it, who were able to view our virtual exhibition. What makes our paper interesting is that it not only presents the state and possibilities of the use of VR technologies, but that it also offers feedback on this topic from a diverse group of people.

\section{Background of the study}

\subsection{Virtual reality as a tool for presenting museum resources}

In recent years, many museums around the world have undertaken the creation of digital exhibitions (for example, the National Museum of Singapore, ${ }^{7}$ State Hermitage Museum in Russia, ${ }^{8}$ and the Tate's recreation of Modigliani's Ochre Atelier ${ }^{9}$ ) and research in this area is conducted by international teams carrying out joint projects, including 3D-ICONS. ${ }^{10}$

Currently, in the broadly understood area of museology, several ways of presenting the content of available exhibitions have been implemented. The most important are:

- via "kiosks": interactive displays made available to visitors within the museum which might present descriptions, scans of documents, photographs, animations of selected

\footnotetext{
${ }^{5}$ 3D Digital Silk Road, accessed 22 January 2020, http://silkroad3d.com/

${ }^{6}$ These interviews were conducted in 2018 and 2019, in the course of events in which authors were participating, and the interviews were accompanied by demonstrations of the relevant technology.

${ }^{7}$ Explore virtual reality at the National Museum of Singapore this weekend - CNA, accessed 10 March 2020, https://www.channelnewsasia.com/news/lifestyle/explore-virtual-reality-at-the-national-museum-of-singapore-this-9481696

${ }_{8}^{8}$ Jupiter Hall VR tour development for State Hermitage Museum, accessed 10 March 2020, https://nntc.digital/ blog/vr-and-ar/jupiter-hall-vr-tour-development-for-state-hermitage-museum-/

${ }^{9}$ Modigliani VR: The Ochre Atelier - Behind the Scenes | Tate, accessed 10 March 2020, https://www.tate.org.uk/ whats-on/tate-modern/exhibition/modigliani/modigliani-vr-ochre-atelier

${ }_{10}$ 3D-ICONS Case Studies, accessed March 10 $0^{\text {th }}, 2020$, https://www.slideshare.net/3dicons/3dicons-case-studies-43942076; 3D-ICONS Guidelines, accessed 10 March 2020, https://www.slideshare.net/3dicons/3dicons-guidelines
} 
K. Żyła - J. Montusiewicz - S. Skulimowski - R. Kayumov: VR technologies...

architectural objects, or other reconstructions based on 3D imaging; ${ }^{11}$

- virtual tours of the museum, often in the form of $360^{\circ}$ panoramas with the option to switch between consecutive views; ${ }^{12}$

- catalogues of segments of the museum's collection made available via the Internet, sometimes as simplified 3D models of objects that can be rotated and scaled; ${ }^{13}$

- via virtual reality (VR) and augmented reality (AR), in which artificially created 2D elements or 3D models are superimposed on the actual camera image.

In 1991, thanks to the work of Tsichritzis and Gibbs, ${ }^{14}$ the concepts of virtual museums (VM) and virtual reality (VR) were introduced into circulation. Although VR seems to be best suited for reconstructing places, ${ }^{15}$ it has potential applications in the context of educational activities ${ }^{16}$ or even in specific cases, such as museums of embroidery, ${ }^{17}$ where $3 \mathrm{D}$ imaging can be mixed with other digitisation technologies. Lepouras et al. provided a useful description of examples of existing virtual environment (VE) systems used in museums that have implemented the idea of VR, exploring the possible degree of user immersion and installation costs. ${ }^{18}$ The authors also presented their approach to creating a stationary VR museum. Another VR application design strategy and MNEME stereoscopic system is introduced by Barbieri et al. ${ }^{19}$ and Bruno et al. ${ }^{20}$

The growing role of mobile devices and systems ${ }^{21}$ has also influenced VR technologies. Jiménez Fernández-Palacios et al. ${ }^{22}$ describe a mobile VR system built in the Unity environment using Oculus Rift, which, in combination with the Kinect driver, allowed users to interact with objects. Another mobile low-cost VR solution for popular smartphones is presented by

\footnotetext{
${ }^{11}$ CALLIERI, Marco et al. Artworks narrating a story: A modular framework for the integrated presentation of three-dimensional and textual contents. In: Proceedings - Web3D 2013: 18th International Conference on 3D Web Technology, 2013 , p. $167-175$.

${ }^{12}$ Khiva360, accessed 10 March 2020, https://khiva360.nazzar.uz/

${ }^{13}$ Cultural Heritage \& History 3D models | Categories - Sketchfab, accessed 10 March 2020, https://sketchfab. com/3d-models/categories/cultural-heritage-history

${ }^{14}$ TSICHRITZIS, Dennis and GIBBS, Simon. Virtual Museums and Virtual Realities. In: International Conference on Hypermedia and Interactivity in Museums, 1991, p. 14-16.

${ }^{15}$ GONÇALVES, Alexandrino et al. An Approach to (Virtually) Recreate Historical Findings. In: Proceedings of the 10th International Congress "Cultural Heritage and New Technologies", Viena, Austria, 2005, p. 1-11.

${ }^{16}$ SANTOS, Filipe et al. Children as Active Partners: Strategies for Collaboration in Spatial Tasks through Virtual Worlds. In: Sixth International Conference on Creating, Connecting and Collaborating through Computing (C5 2008), Poitiers, 2008, p. 73-76; TIŠLIAR, Pavol. The Development of Informal Learning and Museum Pedagogy in Museums. In: European Journal of Contemporary Education, vol. 6 no. 3, 2017, p. 586-592.

${ }^{17}$ SZABÓOVÁ, Nela. Úspechy výšiviek z produkcie Spolku Izabella na medzinárodnom trhu. Muzeológia a kultúrne dedičstvo, vol. 6, no. 1, 2018, p. 95-103.

${ }^{18}$ LEPOURAS, George et al. Building a VR museum in a museum. In: Proc. 2001 VRIC Laval Virtual International Conference, 16-18 May 2001, Laval, France, 2001, p. 1-8.

19 BARBIERI, Loris et al. User-centered design of a virtual reality exhibit for archaeological museums. In: International Journal on Interactive Design and Manufacturing, vol. 12, no. 2, 2018, p. 561-571.

${ }^{20}$ BRUNO, Fabio et al. From 3D reconstruction to virtual reality: A complete methodology for digital archaeological exhibition. In: Journal of Cultural Heritage, vol. 11, no. 1, 2010, p. 42-49.

${ }^{21}$ ŻYLA, Kamil. Attention Deficit Hyperactivity Disorder Detection - from Psychological Checklists to Mobile Solutions. In: Studies in Logic, Grammar and Rethoric, vol. 60, 2019, p. 85-100.

22 JIMÉNEZ FERNÁNDEZ-PALACIOS, Belen et al. Access to complex reality-based 3D models using virtual reality solutions. In: Journal of Cultural Heritage, vol. 23, 2017, p. 40-48.
} 
Skulimowski et al. ${ }^{23}$ Agnello et al. ${ }^{24}$ focus on increased use of VR technologies to prepare virtual tours of historical objects. A classification of application-oriented VR installations that can be used in the area of cultural heritage was introduced by Carrozzino and Bergamasco, ${ }^{25}$ and a six-step procedure for creating VR exposures, with practical notes, has been offered by Remondino et al. ${ }^{26}$ The social consequences of VR technology are explored by Scrofani and Ruggiero, ${ }^{27}$ who point out that its use allows museums to network more effectively within a shared cultural, geographical or thematic area. Finally, the achievements of cyberculture in the fields of education and the presentation and protection of cultural heritage (including technological elements such as VR, 2D and 3D) over the period 2012-2017, are analysed by Župčán. ${ }^{28}$

We are aware that due to the innovative nature of using virtual reality, it would be necessary to properly prepare museum staff and instruct potential content recipients. However, we do not see this as a blocker. What more according to above mentioned literature we could conclude, that the general public awareness about VR technologies is increasing and their setup is not a problem. In addition, the generational shift leads toward people well accustomed to technology being the base for modern VR solutions. From the perspective of the museum staff, operating 3D scanners and software for preparing a VR scene may be challenging, but only apparently. Use of 3D scanners requires manual dexterity rather than specialist technical knowledge. ${ }^{29}$ In case of the software - the main principles of operation should not be a problem for technical employees. At last, we conclude that there is still a lot of space for research on mobile VR technologies as tools for disseminating museum resources, including their effectiveness and acceptance rate by its users.

\subsection{Silk Road museums in Samarkand}

Samarkand is a unique city on the Silk Road ${ }^{30}$ located in the present-day Uzbekistan, which was listed as a UNESCO World Heritage Site in 2001. It owes its exceptional importance mainly to the preserved monumental buildings from the times of the fourteenth-century Mongol conqueror Tamerlane (also known as Timur) and his successors. ${ }^{31}$ The three magnificent

\footnotetext{
${ }^{23}$ SKULIMOWSKI, Stanisław et al. Design and optimisation methods for interactive mobile VR visualisation. In: IOP Conference Series: Materials Science and Engineering, vol. 710, 2019, p. 1-10.

${ }^{24}$ AGNELLO, F. et al. Virtual reality for historical architecture. In: ISPRS Annals of the Photogrammetry, Remote Sensing and Spatial Information Sciences, vol. XLII-2/W9, 2019, p. 9-16.

${ }^{25}$ CARROZZINO, Marcello and BERGAMASCO, Massimo. Beyond virtual museums: Experiencing immersive virtual reality in real museums. In: Journal of Cultural Heritage, vol. 11, no. 4, 2010, p. 452-458.

${ }^{26}$ REMONDINO, Fabio et al. Design and implement a reality-based 3D digitisation and modelling project. In: 2013 Digital Heritage International Congress (DigitalHeritage), 2013, p. 137-144.

${ }^{27}$ SCROFANI, Luigi and RUGGIERO, Luca. Museum networks in the Mediterranean area: Real and virtual opportunities. In: Journal of Cultural Heritage, vol. 14, no. 3, 2013, p. S75-S79.

${ }_{28}^{2}$ ŽUPČÁN, Ladislav. Platforma kultúrneho dedičstva v súčasnej kyberkultúre. In: Muz̨eológia a kultúrne dedičstvo, vol. 7, no. 1, 2019, p. 57-73.

${ }^{29}$ KESIK, Jacek et al. An approach to computer-aided reconstruction of museum exhibits. In: Advances in Science and Technology Research Journal, vol. 11, no. 2, 2017, p. 87-94.

${ }^{30}$ HANSEN, Valerie. The Silk Road: A New History. Oxford University Press, 2012, p. 320; UNESCO, International Institute for Central Asian Studies. Silk Road Memory of the World. Documentary Heritage Inscribe on the UNESCO "Memory of the World" International Register. Mega Basim, 2015.

${ }^{31}$ POLUPANOW, S.N. Architekturnye Pamiatniki Samarkanda. Moscow: Uzdatelistwo Akademii Architektury CCCP, 1948.
} 
K. Żyła - J. Montusiewicz - S. Skulimowski - R. Kayumov: VR technologies...

madrassas (fifteenth to seventeenth century) located on Registan Square, ${ }^{32}$ the Gur-e-Amir mausoleum from 1404 where Tamerlane was buried, the Bibi Chanum mosque complex (fourteenth-century), and the Shah-i Zinda cemetery complex (fourteenth-fifteenth century) are the places most visited by tourists. ${ }^{33}$ The remains of the Ulugh Beg Observatory and the Mausoleum of St Daniel should also not be forgotten. In addition, there are several significant museums in the city, where both ethnographic exhibitions ${ }^{34}$ and artefacts from excavations can be seen, including Afrasiab Museum, the Scientific-Experimental Museum-Laboratory of Samarkand State University and Samarkand Museum of Culture and History.

Afrasiab Museum is located in the ancient city of the same name, which was destroyed in the early thirteenth century by Mongols led by Genghis Khan. The museum contains more than 22,000 unique artefacts found in an excavation site of nearly 200 hectares. Items include glazed plates and dishes, pitchers, ossuaries and skulls of the inhabitants, as well as the famous frescoes known as the Ambassadors' Paintings or the Hall of Ambassadors Murals from the seventh and eighth centuries. ${ }^{35}$

The Scientific-Experimental Museum-Laboratory of Samarkand State University (SamSU) is a museum designed for scientific research and educational purposes. The collection presented in the museum covers pre-Islamic times, the period of development of the city of Afrasiab, as well as the Timuridan period. In addition, a replica of the students' room from the seventeenthcentury madrassa was built in the museum. ${ }^{36}$

The Samarkand Museum of Culture and History has a collection of ancient artefacts, mediaeval ceramics, metal and glassware, as well as numismatic items from Central Asia, ancient Greece and Rome. The museum also has a rich ethnographic collection (about 20,000 pieces) of national clothing, including gold embroidery and carpets, mainly from the nineteenth and twentieth centuries.

The abovementioned museums do not have advanced digital infrastructure or collections digitised using 3D technology. Employees of Lublin University of Technology (LUT), during expeditions to Central Asia (Uzbekistan, Kazakhstan and Kyrgyzstan) in 2017-2019, carried out pilot 3D scans aimed at selecting suitable methods, devices and parameters for a full-scale data acquisition project. On the same trip, LUT employees conducted seminars for academics and students at universities in those countries, presenting various available computer graphics solutions including 3D scanning, 3D printing and interactive virtual walks using mobile VR applications. Numerous conversations with local museum workers, scientists and students indicated a great deal of interest in these solutions, emphasising the importance of virtual

\footnotetext{
${ }^{32}$ MILOSZ, Marek et al. Determination of ceramic tile colour surface areas on the medieval Sher-Dor Madrasah mosaic in Samarkand - Problems and solutions. In: Digital Applications in Archaeology and Cultural Heritage, vol. 16, 2020, p. 1-6.

${ }^{33}$ ARAPOW, A. and GLAUDINOV, B. The Artistic Culture of Central Asia and Azerbaijan in the 9th-15th Centuries, vol. IV: Architecture. International Institute for Central Asia Studies, 2013, p. 159-215; RAKHMANOW, Abusapikhan. Architectural Monuments of Samarkand in the Timurid Epoch. In: Proceedings of the Workshop on Conservation and Management of Timurid Architecture, 21 April- 2 May 2008, Tashkent, Samarkand, Shakhrisyabz, Bukhara, Khiva, Mega Basim, 2008, p. 32-43.

${ }^{34}$ ORIFJONOVA, Gulra'no Ravshan. Ethnographic collections of museums in Uzbekistan: samples of copper-embossing art. In: Muzeológia a kulturne dedičstvo, vol. 7, no. 1, 2019, p. 235-240.

${ }_{35}$ AZARPAY, Guitty. The Afrasiab Murals: A Pictorial Narrative Reconsidered. In: The Silk Road, vol. 12, 2014, p. 49-56.

${ }^{36}$ MONTUSIEWICZ, Jerzy et al. The concept of low-cost interactive and gamified virtual exposition. In: INTED2018 Proceedings, 2018, p. 353-363.
} 
exhibitions for mobile devices, and motivating the authors to undertake the research presented in this article.

\section{Virtual exhibition development}

For the purpose of our research, and on the basis of the literature review, as well as market research and analysis of the operation of various distribution platforms, we assumed that the VR application to be created will most commonly be used on mobile smartphones with the Android operating system. In this way, we hoped to ensure maximum availability of the created content for potential recipients, due to:

- the possibility for users to use their own devices (minimum requirements - Android version 5.0, magnetometer, Bluetooth, full HD screen between 4 and 6 inches) instead of having to purchase additional computer and projection equipment;

- the application's uncomplicated configuration for use (after installation, the application only requires users to define the profile of whichever VR frame they own);

- an uncomplicated hardware configuration (the application requires a smartphone, a VR frame and a Bluetooth joystick for operation - no additional cables etc. are needed).

We used the following tools during the development of our virtual exhibition:

- Google VR SDK as the main component responsible for image transformation and interactions generated by the application for the purpose of VR presentation running on an Android device;

- $\quad 3 \mathrm{~d}$ Max environment for processing acquired 3D scans and creating background objects;

- Unity graphics engine for creating a virtual scene and embedding application logic;

- Visual Studio development environment for creating scripts in the C\# language, describing the logic of the application's operation (including interaction methods and their results).

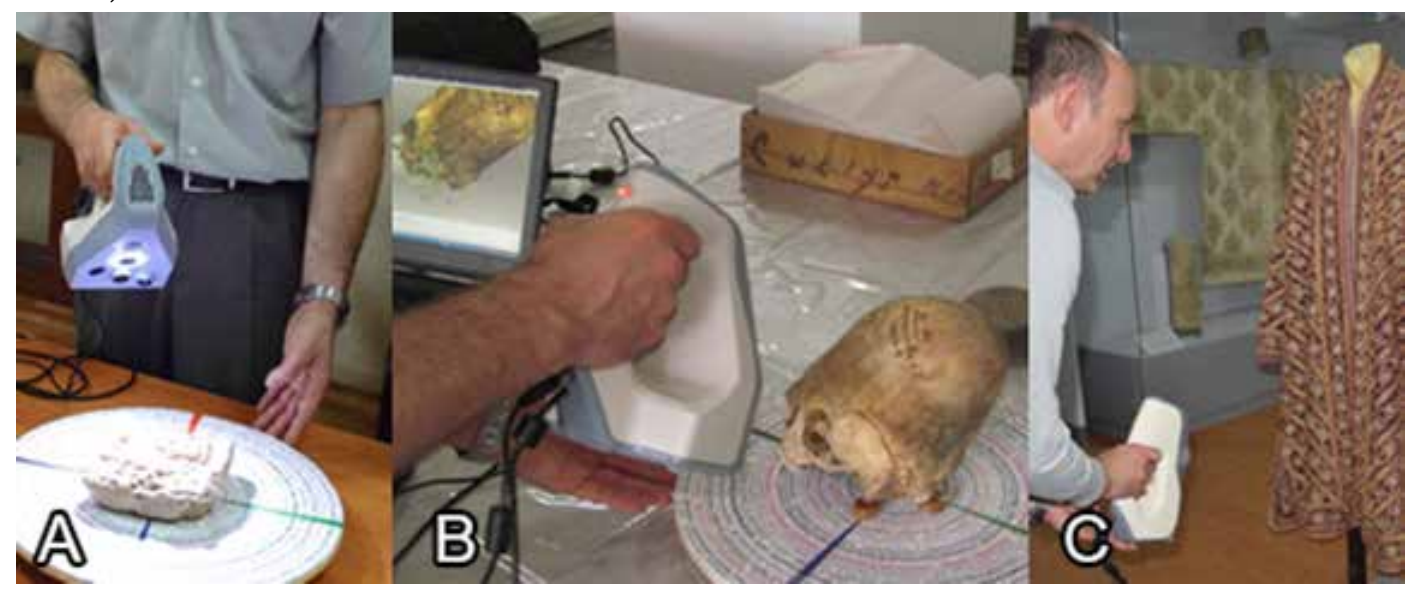

Figure 1: 3D Digitisation: a) Scientific-Experimental Museum-Laboratory (SEML), b) Afrasiab Museum, c) Samarkand Museum of Culture and History (SMCH)

First of all, a general application skeleton was developed which could later be adapted to specific applications, such as 3C (cross-culture competence) studies. Next, the preparation of 
K. Żyła - J. Montusiewicz - S. Skulimowski - R. Kayumov: VR technologies...

3D models and designing the interior of virtual rooms began.

The models of the exhibits placed on the virtual stage came from three Samarkand museums and were acquired by means of 3D scanning (Figure 1). The digitisation process was performed by LUT employees with professional 3D scanners that use structural light: namely, Artec Eva and Artec Spider. These offered 3D point accuracy up to $0.1 \mathrm{~mm}$ and $0.05 \mathrm{~mm}$ respectively. The models acquired were initially recorded in the form of point clouds with textures, and then processed in LUT's "Lab3D" laboratory in the form of triangular meshes. Figure 2 presents examples of exhibits at different stages of processing.

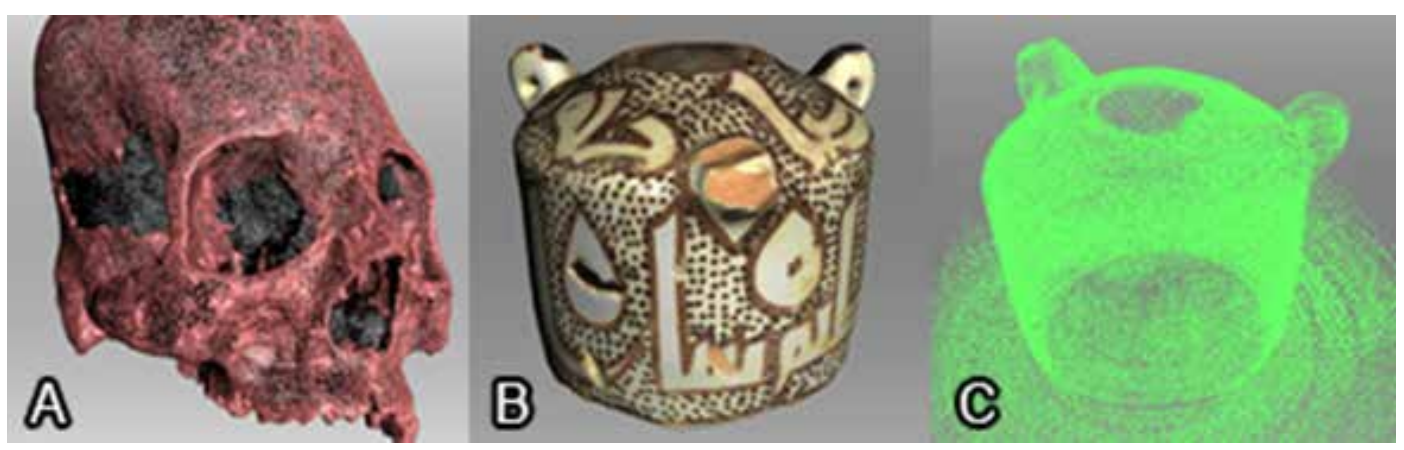

Figure 2: Afrasiab Museum - 3D digital models: a) skull, second century CE - net model, b) glazed olive lamp, eleventh to twelfth century - photorealistic model, c) point cloud of the lamp object

Twelve objects were placed in four rooms in the virtual scene (Figure 3), including four objects from the Scientific-Experimental Museum-Laboratory (jugs and a vessel for transporting mercury); seven from Afrasiab Museum (a ritually deformed skull, jugs, a glazed plate and an olive lamp); and one from Samarkand Museum of Culture and History (a nineteenth-century garment of Emir of Bukhara, embroidered with gold thread). The objects were selected to (1) present the diversity of Uzbekistan's cultural heritage through artefacts from the second to the nineteenth century; (2) be visually appealing to the average observer who might not be familiar with the culture of the region; and (3) present different objects in terms of how they are scanned and processed.

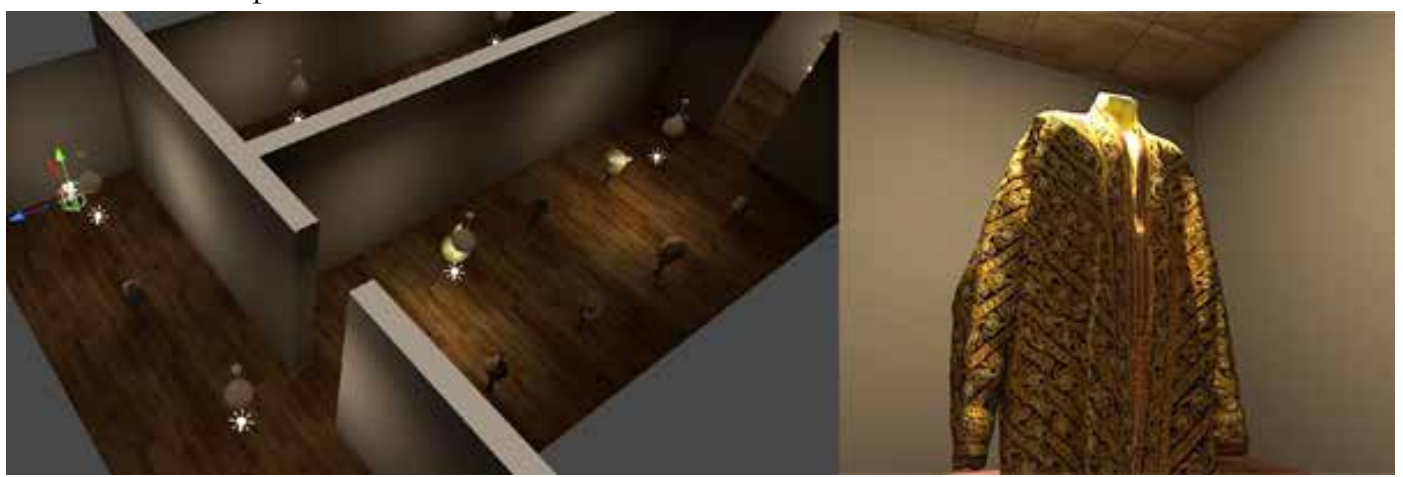

Figure 3: View of the virtual scene in the Unity environment: left - view of the entire complex; right-view of Emir of Bukhara garment from the observer's perspective

The relatively small computing resources of smartphones demanded action to facilitate the smooth running of the application. For this reason, the VR walk was limited to four rooms 
and 12 objects. This reduced the average duration of the VR session for the participant, which resulted both in lower battery consumption and less risk of overheating the smartphone. All analytical scripts (written for the purpose of collecting data about participants' movement and actions) and interaction mechanisms were developed to be executed as rarely as possible and to make optimum (i.e. minimal) use of the device's memory. The 3D models were optimised (simplifying geometry by reducing the number of triangles and simplifying the texture) using manual and automatic techniques, in similar ways to previous projects the team had carried out. ${ }^{37}$ All modifications of the $3 \mathrm{D}$ models were discussed with representatives of the museum community, to ensure that the important details of the exhibits were preserved.

\section{Methodology}

The main goal of this paper is to provide insight into the preferences of the general community interested in the cultural heritage of the Silk Road with regards to the idea of presenting museum exhibitions in virtual reality. Another goal is to identify the possible roles (either complementary or supplementary) that could be played by VR technology in context of traditional museum exhibitions. To achieve these goals, we decided to conduct exploratory research among a highly internationalised group of people - museum professionals involved in the management of Silk Road heritage and individuals interested in the cultural heritage of that region.

Before we introduce the research questions, two basic notions must be explained: the traditional and the virtual exhibition. From this point on, when we write "virtual exhibition", we have in mind a museum exhibition made using virtual reality (VR) technologies, consisting of digital representations of real objects, in which the viewer is put into a state of immersion using a specialised headset. By "traditional exhibition" we mean an exhibition that can be visited at the site of the museum, consisting of real objects, as well as audiovisual content, photographs, educational games and so on. In this type of exhibition, the viewer does not enter a state of immersion using any kind of VR equipment.

After analysing the situation concerning the use of VR technologies by Silk Road museums, we formulated the following research questions:

RQ1.Is the use of VR technologies a good complement to traditional museum exhibitions?

RQ2.Can the use of VR technologies improve accessibility of a museum exhibition's content?

RQ3.Can VR technologies lead to increased interest in museum exhibitions?

In order to answer these research questions, we took a bidirectional approach, conducting a set of interviews with professionals and a regular experiment involving young adults belonging to Generation Z.

The first direction involved face-to-face interviews with professionals from the regions connected by the Silk Road, including, but not limited to, those working in the museums around Samarkand, Uzbekistan. Interviews were conducted in 2018 and 2019, during events on the heritage of the Silk Road in which the authors were participating, ${ }^{38}$ and were accompanied by demonstrations of the technology under discussion. The interviews were conducted as informal

\footnotetext{
${ }^{37}$ SKULIMOWSKI, Stanisław et al. Design and optimisation ..., 2019, p. 1-10.

${ }^{38}$ The list of events can be found in the newsletter of the Department of Computer Science, Lublin University of Technology (https://cs.pollub.pl/news/?lang=en), as well as at http://silkroad3d.com/
} 
K. Żyła - J. Montusiewicz - S. Skulimowski - R. Kayumov: VR technologies...

meetings in quiet, separated places; questions were put to the participants and their answers recorded. The questions concerned the characteristics of the respondent, the possibility of virtual exhibitions either replacing or complementing traditional ones, the ability of virtual exhibitions to improve the accessibility of museum resources to the general public, and the ability of virtual exhibitions to increase the general public's interest in museum resources. The unique example of the Silk Road museums and their exhibitions was the background for the questions.

The second research direction, carried out in 2019, was a regular experiment involving young adults belonging to Generation Z (born between 1995 and 2001) who were interested in cultural heritage and innovative methods of presenting it. The experiment was divided into two parts: participants first viewed our virtual exhibition and then filled in a survey. All respondents were university students. We made significant efforts to seek the opinions of people from highly varied backgrounds - from a variety of countries, from at least 10 different parent universities (including foreign exchange students) and studying different subjects at university - in an attempt to counteract any bias in the results caused by selecting respondents of a homogeneous origin. We selected participants by asking them if they were interested in cultural heritage and in innovative methods of presenting it, in hope that they would want to be more involved in the research process and would express their opinions more freely and expansively.

For the purpose of the experiment we created a virtual exhibition presenting 3D-scanned museum objects from Samarkand. The exhibition was prepared using a Unity graphics engine and Google VR SDK for the Android platform. To demonstrate it, we used a Redmi Note 5 smartphone placed in a VR BOX frame (Figure 4) which was worn on the participant's head. Additionally, we provided respondents with a Mocute-050 Bluetooth controller to facilitate their movement across the exhibition. Thanks to the mobile character of this equipment, we had plenty of flexibility as to the location for the experiment: a computer laboratory was as suitable as a plain classroom or a conference room, as long as we were able to provide the participant with (1) a choice of posture - sitting or standing; (2) freedom of movement within the adopted posture; and (3) the absence of adverse environmental factors (noise, vibrations, smells, crowds and so on).

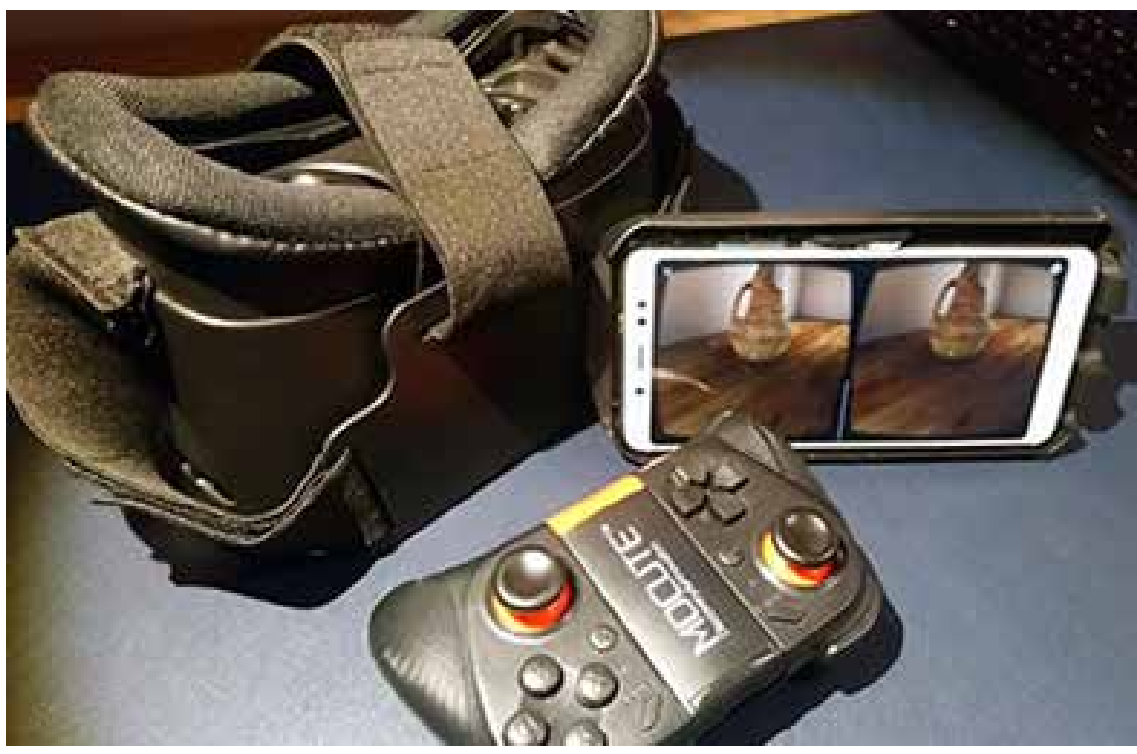

Figure 4: The test setup: VR frame, Bluetooth controller with joystick, $A n$ droid mobile device - image displayed on the smartphone with a division into left and right eye 
Our virtual exhibition consisted of four rooms. The first was a playground where the respondent could quickly become accustomed to our VR environment, learning how to move and display information about the presented objects; this usually took just a few minutes. The main sightseeing tour began with the second room. The time participants could spend in the exhibition was not limited, although due to its small size no respondent spent longer than 20 minutes - which was in accordance with our objectives when designing the exhibition. During the process, we monitored the respondents' movements in order to determine how much of the exhibition they visited and whether their answers were credible when they filled in the survey.

The second part of the experiment was the survey, which could be filled in only after finishing the VR demonstration. The survey covered demographic questions (age, sex, country of origin, course of studies, experience using VR, interest in cultural heritage) and then posed the following questions: ${ }^{39}$

Q1. Do you think that VR is a good way to complement a traditional exhibition?

Q2. Do you think that VR could become the basic method of presenting museum resources?

Q3. Do you think that a virtual exhibition could make you want to visit a traditional exhibition?

Q4. Do you think that availability of virtual exhibitions would make it easier for you to plan your visit to selected museums and exhibitions?

Q5. Imagine you did not have enough time to finish going round a traditional museum exhibition. Do you think that you could finish it using a virtual exhibition?

Q6. After seeing this virtual exhibition, do you feel encouraged to see another one?

Q7. Based on your whole experience, what is your level of satisfaction with virtual exhibitions?

For questions Q1 to Q7, respondents were first asked the question, then to rate how much they liked the idea on a scale of 1 to 5 ( 5 being the most positive response) as an answer. We chose this approach instead of the 5-degree Likert scale, in order to obtain ordered values of constant interval being 1 . This approach makes it easy for respondents to express answers, and also simplifies the statistical analysis. Respondents were also able to freely add their comments and remarks to the survey, thus were not limited by its authors' imagination.

To present the distribution of data we used a classical histogram and box plot diagrams, depicting the first and third quartiles, median and whether outlying values were present. To identify any correlations between responses to the main questions and respondents' demographic profiles (country of origin, sex) we used a Pearson's Chi-squared test of independence, followed by Goodman's Kruskal Tau test to check for effect size (strength of association). In the case of respondents' interest in cultural heritage and experience with VR, we used Spearman's rank correlation coefficient (rho). For each statistical test, the level of significance was set to 0.05 . We used the R 3.6.2 environment for statistical computations and generation of plots presenting the analysed data.

\footnotetext{
${ }^{39}$ Our research was of a broader scope than the topic of this article. We only mention questions (and other data) that are within the scope of this article.
} 
K. Żyła - J. Montusiewicz - S. Skulimowski - R. Kayumov: VR technologies...

\section{Results}

\subsection{Interviews with professionals}

As outlined above, we conducted in-person interviews with influential professionals interested and/or involved in activities relating to the cultural heritage of regions connected by the Silk Road, including professionals who worked in museums in and around Samarkand, Uzbekistan. Their feedback, although unstructured, gave us many valuable ideas which were used when writing questions for the survey with younger respondents which formed the second part of our study.

We interviewed 20 people in total: 3 from Poland (none of whom worked for the Lublin University of Technology), 3 from Japan, 7 from Uzbekistan (including directors of partnering museums), 4 from Kazakhstan and 3 from Kyrgyzstan. The interviewees were mostly men, with only 3 women (from Poland, Uzbekistan and Kyrgyzstan). We reached wide variety of professionals, from policy makers and directors to regular museum workers. Our respondents fell broadly into three age categories we can define as younger, middle-aged and older, with the youngest respondents in their 30s and the oldest in their 70s. Since the interviews were brief and informal, and were conducted with people from a variety of cultural backgrounds, we were concerned that asking directly about respondents' age might be perceived by some as inappropriate, so instead we relied on these broad categorisations.

Despite the fact that our interviews were unstructured, we were able to collect enough data to quantify responses to an extent, by extracting the common topics and classifying the opinions. The experience of $45 \%(9 / 20)$ of respondents with VR technologies was classified as moderate; ${ }^{40}$ the remaining $55 \%(11 / 20)$ had a low level of experience. ${ }^{41}$ On analysing the content of the interviews, we did not observe significant influence of the respondent's country of origin or level of VR experience on the opinions expressed.

In RQ1, we asked whether VR technologies offer a good complement to traditional museum exhibitions. $79 \%$ of respondents (15/19) said that using VR is a very good idea, while $21 \%$ $(4 / 19)$ were not convinced that VR has a significant role to play, although they were not against it. $75 \%(15 / 20)$ of respondents did not expect VR technologies to become the main method of presenting museum resources. Typical justifications included the limitations of the technology, its inability to act as a full substitute for personal travel to a museum, and the overwhelming number of tourists visiting museums in person - making use of real-world, not virtual, reality. Nevertheless, it must be acknowledged here that we are constantly seeing a shift towards the information society, and that this could radically change the way museums are perceived, unless we educate people to treasure the current culture of visiting museums.

In RQ2 we asked whether VR technologies could improve the accessibility of museum resources to the broader public, especially in case of the Silk Road. Most of the evidence on this is qualitative in its nature, as it is related to the specificity of technology and the provision of access to those who are unable to visit the museum in person for a variety of reasons, such as disability, poverty, being forbidden to visit a particular country or disinclination to travel. Some indirect evidence was provided by the following responses which emerged from the

\footnotetext{
40 "Moderate" experience $=$ the respondent knows essentially what VR is, knows what kind of equipment is needed, understands how to run a VR application, and knows what main steps are and what artefacts are needed to create a VR application. Such a person will have personal experience of exploring a virtual reality environment, but does not have thorough knowledge of the aforementioned aspects and is not able to create VR applications themself. 41 "Low" experience $=$ the respondent only roughly knows the idea and purpose of VR, and has at least once been shown a demonstration of the technology.
} 
interviews. $65 \%(13 / 20)$ of respondents felt that broadly accessible virtual exhibitions would be very helpful when planning a trip and choosing attractive places to visit, especially in the case of the highly scattered Silk Road museums. The remaining 35\% (7/20), which included both younger and older respondents, were sceptical about whether VR could be of help. It is unclear whether their responses referred only their personal preferences, or whether they also tried to encapsulate the heterogeneity of all tourists of varied ages, preferences and so on. Finally, respondents discussed the idea of being able to finish sightseeing based on a virtual version of the exhibition where they were unable to complete their viewing of a traditional one, for example, due to the museum's closure, the late hour or to public transport schedules. $74 \%(14 / 19)$ said words to the effect of "Why not?" before noting that the experience would not be equal to visiting the traditional exhibition. The remaining 26\% (5/19) did not agree that it was a good idea.

In RQ3 we asked whether VR technologies can increase interest in museum exhibitions. $25 \%(5 / 20)$ of respondents claimed that viewing a virtual exhibition would strongly influence their decision to visit a traditional one, 50\% (10/20) were doubtful about whether a virtual exhibition would be the deciding factor and $25 \%(5 / 20)$ felt it would be irrelevant to their decision to visit a traditional exhibition. However, 85\% (17/20) of respondents, after seeing the technology demonstrated, said they were interested in seeing another virtual exhibition. Respondents frequently mentioned the visual quality of the virtual exhibition and how easy it was to move around it as major factors determining its success. The responses of interviewees suggested generally that VR seems to be seen as a "catchy" and promising idea in the opinion of museum professionals. Including virtual exhibitions as part of its offer can also potentially improve the perception of a museum as prestigious, professional and modern, although it must not be forgotten that the quality of the VR offer can be a factor in either encouraging or discouraging interest in a particular museum, especially in case of young people, who are increasingly dependent on technology.

Aside from above-mentioned quantifiable data we were also able to extract more general thoughts expressed in the interviews. Directors of museums usually asked us about the cost of equipment and personnel training, as well as the technical requirements for deploying VR technologies in their museum. Regular museum workers were concerned about the usability aspects of virtual exhibitions and what training they would need in order to create and maintain virtual exhibitions. The oldest interviewees were concerned about technological barriers, which was not a concern among the youngest respondents; in fact, the younger interviewee was, the less problematic technology was for them. People who had noticeable experience in virtual reality emphasised that, due to the performance limitations of current endpoint devices, the ultra-realistic quality of a virtual exhibition (sound, graphics, smells, heat, etc.) might be impossible to achieve. They also mentioned the price of certain high-quality VR headsets as prohibitive. All of interviewees valued the role that virtual exhibitions might play in helping people access the assets of the Silk Road museums, which are scattered over long distances and thus expensive and difficult for tourists to visit. However, they also constantly highlighted the benefits and joy of visiting expositions in person and experiencing the atmosphere of real places - something that, in their opinion, cannot be fully achieved via virtual substitutes. 


\subsection{Experiment with Generation Z}

In the second direction of our research, we aimed to investigate the attitudes of young people (Generation Z) interested in cultural heritage towards VR technologies and virtual exhibitions. This is very important aspect of our research, because these people will replace older generations as the future visitors to all kinds of museums.

Our experiment involved 50 individuals from nine countries, with 26 from Poland and 24 from other countries. The exact distribution of respondents' country of origin is presented in Figure 5. There were 36 men and 14 women. Age was limited at the planning stage to those who were adults according to Polish law (over 18 years of age) but born in 1995 or later. All respondents met these constraints. We asked our respondents to rate (from 1 to 5 , where 5 is the highest) their interest in cultural heritage (CH) and their experience with VR technologies (VR). Results are presented in Figure 6. As the histogram on the right shows, respondents' declared experience with VR was rather low, although the sample included a significant number of people with medium and high experience. Interest in cultural heritage, declared by respondents, was quite high and meets assumptions of our experiment.

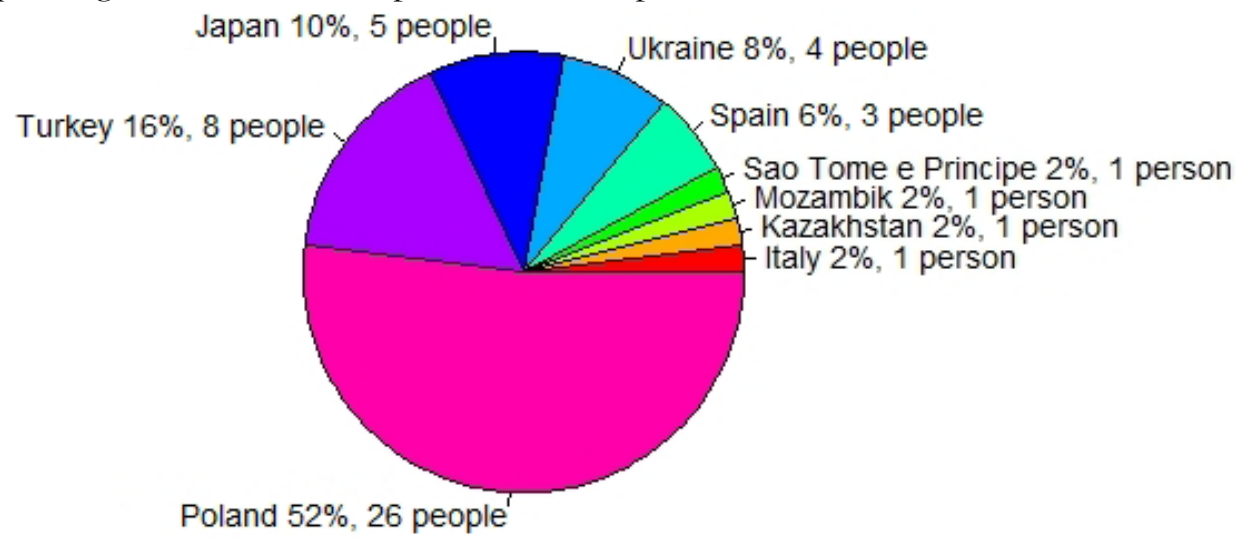

Figure 5: Respondents' country of origin
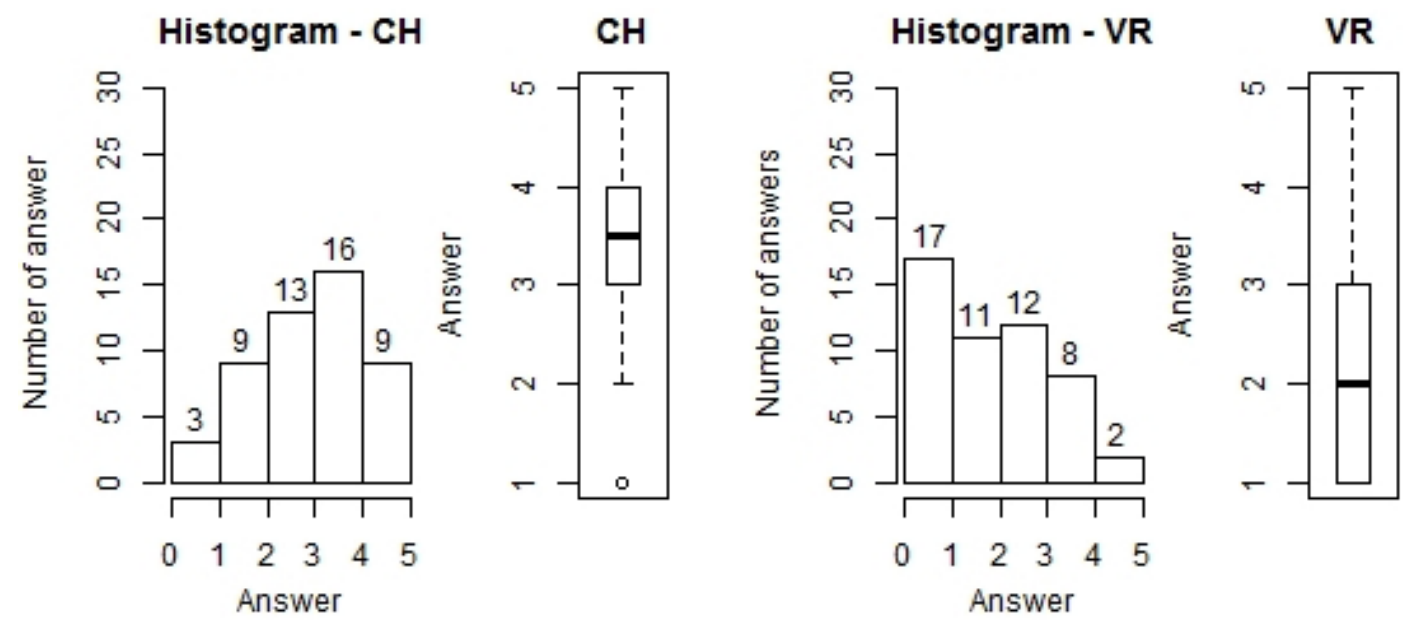

Figure 6: Distribution of respondents' interest in $\mathrm{CH}$ (cultural heritage) and experience with VR 
We tracked respondents' movements as they explored the VR exhibition, and this data allowed us to conclude that all participants fully completed the virtual walk; that is, they visited all of the rooms and showed interest in the 3D models of artefacts from Samarkand that were presented to them. Next, they were asked the questions described in the methodology section. The answers were expressed as numbers from 1 to 5,5 being the most positive response. Figure 7 presents histograms of answers for questions Q1 to Q7. Figure 8 presents box plots depicting the distribution of answers for questions Q1 to Q7.

According to respondents, VR is a good way to complement a traditional exhibition - the mode value for Q1 was 4; 62\% of respondents rated this idea as 4 or 5. Only minor optimism was shown regarding the use of virtual exhibitions as the basic method of presenting museum resources (Q2) - the mode here was also 4, but only 44\% of respondents rated this idea as 4 or 5. Answers to Q7 confirmed the important role of VR, as $63 \%$ of respondents rated their lifelong experience with VR as 4 or 5 , the mode value being 4 .

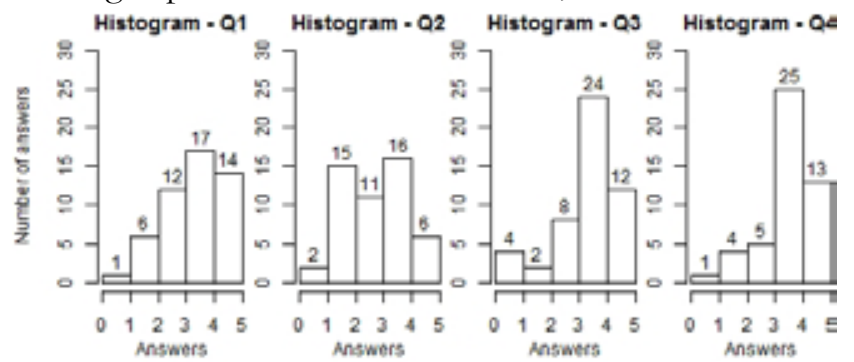

Qualitative evidence for VR technologies improving the accessibility of museum resources has already been discussed above - the assumptions made there apply here as well. Nevertheless, we asked respondents about two cases involving the use of VR revealed during the interviews

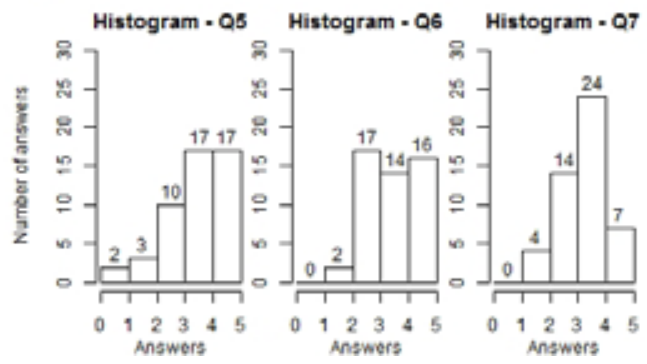
with professionals. Many respondents stated that virtual exhibitions would be very helpful when planning a trip and choosing attractive places to visit (Q4) - the mode value was $4 ; 79 \%$ of respondents rated this idea as 4 or 5 . Similarly, the idea of finishing a visit to an exhibition that Figure 7: Distribution of respondents' answers to questions $Q^{1-Q 7}$ had been interrupted by means of a virtual exhibition (Q5) was well received - the mode values were 4 and 5; 69\% of respondents rated the idea as 4 or 5 . However, we have to acknowledge here that $52 \%$ of respondents claimed in comments ${ }^{42}$ that they would prefer the traditional way of viewing an exhibition, as VR is not able to provide the same experience and atmosphere.

Next, it was revealed that virtual exhibitions are good tools for advertising (that is, encouraging people to visit) traditional ones (Q3) - the mode value was $4 ; 72 \%$ of respondents rated the degree to which they would be encouraged as 4 or 5. Surprisingly, respondents' opinions on whether they would be encouraged to see another virtual exhibition after seeing the previous one (Q6) were not so straightforward - the mode value was 2, but $61 \%$ of respondents rated the degree to which they would be encouraged as 4 or 5 .

${ }^{42}$ Comments were optional, thus this number might be even higher in reality. 


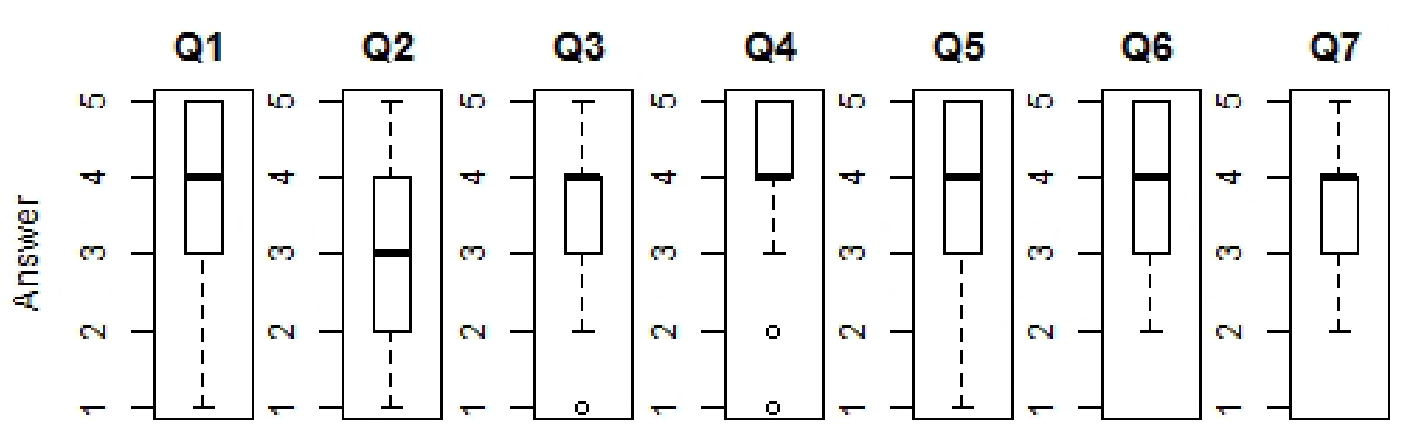

Figure 8: Box plots showing distribution of respondents' answers to questions $Q^{1-Q^{7}}$

The results of the statistical dependency tests can be found in Table 1. We did not find that respondents' country of origin influenced their answers to questions Q1-Q7 to any statistically significant degree. For each question we were unable to discard the null hypothesis (H0) that the two variables were independent (for each question, $\mathrm{p}$-value $>0.05$ ). Moreover, the tau value in each case indicated a negligible strength of association. Similarly, no dependence was found between respondents' sex and their answers, with one exception: a statistically significant dependence was revealed between sex and level of satisfaction with virtual exhibitions ( $\mathrm{p}$-value $=0.03$; H0: the two variables are independent) but the strength of association was negligible $(\operatorname{tau}=0.10)$. Moreover, we cannot conclude that respondents' interest in cultural heritage was correlated with their answers, with one exception - a statistically significant positive correlation of moderate strength in the case of question Q7, meaning that people who rated their interest in cultural heritage more highly also registered a high level of satisfaction with virtual exhibitions. Finally, we found no evidence that experience with VR was in any significant way correlated with respondents' answers. For each statistical test, the level of significance was set as 0.05.

In summary, according to the data collected during the experiment, we could answer positively to all of our research questions. What is more, our findings concerning Generation $\mathrm{Z}$ are in line with conclusions made after analysing the interviews with museum professionals.

\begin{tabular}{|l|l|l|l|l|l|l|l|l|}
\hline Country of origin & p-value & 0.13 & 0.18 & 0.52 & 0.24 & 0.48 & 0.55 & 0.10 \\
\cline { 2 - 9 } & tau & 0.16 & 0.19 & 0.14 & 0.20 & 0.19 & 0.15 & 0.18 \\
\hline \multirow{2}{*}{ Sex } & p-value & 0.23 & 0.42 & 0.34 & 0.37 & 0.45 & 0.74 & 0.03 \\
\cline { 2 - 9 } & tau & 0.04 & 0.02 & 0.03 & 0.02 & 0.02 & 0.00 & 0.10 \\
\hline \multirow{2}{*}{$\begin{array}{l}\text { Interest in cultural heri- } \\
\text { tage }\end{array}$} & p-value & 0.02 & $0.01>$ & 0.82 & 0.15 & 0.01 & 0.13 & $0.01>$ \\
\cline { 2 - 10 } & rho & 0.32 & 0.36 & 0.03 & 0.21 & 0.35 & 0.22 & 0.46 \\
\hline \multirow{2}{*}{ Experience with VR } & p-value & 0.29 & 0.69 & 0.50 & 0.08 & 0.69 & 0.17 & 0.67 \\
\cline { 2 - 9 } & rho & 0.15 & -0.06 & -0.10 & -0.26 & 0.06 & -0.20 & 0.06 \\
\hline
\end{tabular}

Table 1: Dependency among respondents' characteristics and answers to survey questions

\section{Conclusions}

Based on the feedback we gathered, we can predict that virtual exhibitions will provide a good complement to traditional museum-based exhibitions. Museum professionals need not fear that VR will entirely replace traditional exhibitions in the near future. Most respondents (from both the experiment and the interviews) were unenthusiastic towards the idea of using virtual exhibitions as the basic method of presenting museum resources. Their opinions were based on the fact that VR is not able to fully replicate the atmosphere of visiting a real 
exhibition at a museum. This could be interpreted as a result of the whole culture and set of emotions currently associated with visiting museums. Contemporary VR technologies are not able to fully replicate these emotions and or the stimuli that generate them, due to limitations on the level of detail, freedom of movement, smell, humidity, temperature, and the sense of a tangible experience of history, among others. Will this change in future, when the generation who do not know the life without the Internet are dominant? That depends on whether we are able to educate them to treasure the current culture of visiting museums.

When it comes to increasing the accessibility of museum resources, respondents mentioned some interesting cases where virtual exhibitions can complement, in a special way, traditional approaches to sightseeing. For example, they offer the ability to finish a museum visit that was interrupted for whatever reason; they can help people to choose especially interesting places to visit; and they can be a useful aid when planning a sightseeing route in detail. Another aspect of accessibility is the protection of cultural and natural heritage from destruction due to natural disasters, military operations or other man-made disasters. Thanks to 3D scanning techniques, as well as photogrammetry (a less precise approach), we can obtain and preserve a huge amount of spatial information which is unattainable by classic photography or film. It is possible to reproduce, dimension, maintain and renovate real objects based on their digital form. Virtual exhibitions are also a part of this accessibility aspect.

Respondents indicated clearly that they value the potential of VR technologies in the context of creating virtual museum exhibitions, and that virtual exhibitions could satisfy them in the above-mentioned cases, although to a limited degree. The majority also agreed that virtual exhibitions could potentially increase their interest in traditional exhibitions, which is good news for museums, as it suggests that ICT and traditional museology techniques can coexist, rather than the displacement of traditional museology techniques by digital technologies. In addition, with the ability to access to digital materials in advance, visitors from abroad with an interest in cultural heritage will be able to better plan their stay, which will further promote cultural heritage sites - and in particular the Silk Road heritage sites.

One very important group of people - unfortunately not covered by our research - consists of individuals who are unable to visit a traditional museum exhibition for various reasons, such as disability or legal prohibitions. It is of particular significance in case of the Silk Road heritage, which is dispersed not only in terms of distance, but also located across several highly diverse countries. In this case, virtual exhibitions can provide a substitute for onsite visits, or they can complement materials (such as photos and films) available, for example, on the museum's website. The availability of a virtual exhibition automatically improves access to the museum's resources for those who cannot visit in person. Whether VR technologies can increase such people's interest in a museum exhibition is not so obvious. On the one hand, they do not have much choice of methods for exploring the heritage of the Silk Road; on the other hand, there is the matter of their personal preferences, which might or might not be affected by issues such as medical conditions.

We did not record a significant number of opinions indicating dissatisfaction with the visual quality of the objects presented on our virtual exhibition. Some voices of dissatisfaction naturally appeared, but they tended to focus on the technical limits of VR graphics rather than the actual loss of visual quality as a result of compressing the $3 \mathrm{D}$ model to a size acceptable for a typical mobile device, so that device could handle the entire scene consisting of many rooms and objects. In discussions, some respondents emphasised the importance of sounds and small 
K. Żyła - J. Montusiewicz - S. Skulimowski - R. Kayumov: VR technologies...

objects not directly related to the exhibition, but they expressed these opinions only in response to our questions. Therefore, we can assume that these are not the most important elements of the exhibition, although we will explore this topic in future work.

The inclusion of virtual exhibitions based on VR technologies in their offer represents a kind of revolution for museums; it requires mental readiness for change among staff, as well as expenditure on training, equipment and ICT infrastructure. At the same time, we have communities ready for the digital revolution, and various governments around the world are taking action to protect their heritage by digitising objects in 3D. Using VR technologies to develop virtual exhibitions in the form presented in this article is not only affordable, but also in line with these actions.

It should be added here that the current events taking place at the time of writing - namely, the global coronavirus pandemic - will undoubtedly contribute to the reconceptualisation of how museums function and will change the current paradigm of preparing museum exhibitions for domestic and foreign guests. It can be assumed with a high degree of certainty that, just as distance learning is developing, so the implementation and development of new ICT technologies will allow virtual guests to visit museums from a distance and will provide better levels of satisfaction than are seen at present.

In summary, on the basis of interviews, discussions and surveys, and in the context of the presented case study, we conclude that the use of VR technologies as an extension to existing museum exhibitions 1) improves the availability of the exhibition, and 2) should lead to increased interest in the exhibition. VR technologies have, in the presented case study, proven to offer a good complement to the traditional exhibition. Naturally, the results of our research cannot be uncritically generalised to apply to the entire population, but we believe that these results were delivered based on an interesting and diverse group of respondents.

\section{Acknowledgments}

The authors wish to thank the directors and employees of the Afrasiab Museum, the Samarkand Museum of Culture and History and the Scientific-Experimental MuseumLaboratory of Samarkand State University for their assistance in this research and for making museum artefacts available for 3D scanning.

The research program titled "Usability studies of museum exhibitions created in the virtual reality environment" was approved by the Commission for Research Ethics, No. 3/2017 dated 19 December 2017.

\section{References}

AGNELLO, F., AVELLA, F., AGNELLO, S. (2019). Virtual reality for historical architecture. In: ISPRS Annals of the Photogrammetry, Remote Sensing and Spatial Information Sciences, vol. XLII2/W9, p. 9-16. DOI 10.5194/isprs-archives-XLII-2-W9-9-2019

ARAPOW, A., GLAUDINOV, B. (2013). The Artistic Culture of Central Asia and Azerbaijan in the 9th-15th Centuries, vol. IV: Architecture. International Institute for Central Asia Studies, Samarkand-Tashkent, p. 159-215. ISBN 978-9943-357-13-6.

AZARPAY, Guitty (2014). The Afrasiab Murals: A Pictorial Narrative Reconsidered. In: The Silk Road, vol. 12, 2020, p. 49-56. ISSN 2152-7327. 
BARBIERI, Loris, BRUNO, Fabio, MUZZUPAPPA, Maurizio (2018). User-centered design of a virtual reality exhibit for archaeological museums. In: International Journal on Interactive Design and Manufacturing, vol. 12, no. 2, p. 561-571. DOI 10.1007/s12008-017-0414-z

BRUNO, Fabio, BRUNO, Stefano, DE SENSI, Giovanna, LUCHI, Maria Laura, MANCUSO, Stefania, MUZZUPAPPA, Maurizio (2010). From 3D reconstruction to virtual reality: A complete methodology for digital archaeological exhibition. In: Journal of Cultural Heritage, vol. 11, no. 1, p. 42-49. ISSN 1296-2074. DOI 10.1016/j.culher.2009.02.006

CALLIERI, Marco, LEONI, Chiara, DELLEPIANE, Matteo, SCOPIGNO, Roberto (2013). Artworks narrating a story: A modular framework for the integrated presentation of threedimensional and textual contents. In: Proceedings - Web3D 2013: 18th International Conference on 3D Web Technology, p. 167-175. ISBN 9781450321334.

CARROZZINO, Marcello, BERGAMASCO, Massimo (2010). Beyond virtual museums: Experiencing immersive virtual reality in real museums. In: Journal of Cultural Heritage, vol. 11, no. 4, p. 452-458. ISSN 1296-2074. DOI 10.1016/j.culher.2010.04.001

GONÇALVES, Alexandrino, SILVA, Fernando, MENDES, António José (2005). An Approach to (Virtually) Recreate Historical Findings. In: Proceedings of the 10th International Congress "Cultural Heritage and New Technologies", Viena, Austria, p. 1-11.

HANSEN, Valerie (2012). The Silk Road: A New History. Oxford University Press, p. 320. ISBN 9780195159318.

JIMÉNEZ FERNÁNDEZ-PALACIOS, Belen, MORABITO, Daniele, REMONDINO, Fabio (2017). Access to complex reality-based 3D models using virtual reality solutions. In: Journal of Cultural Heritage, vol. 23, p. 40-48. ISSN 1296-2074. DOI 10.1016/j.culher.2016.09.003

KE్SIK Jacek, MONTUSIEWICZ, Jerzy, KAYUMOV, Rahim (2017). An approach to computer-aided reconstruction of museum exhibits. In: Advances in Science and Technology Research Journal, vol. 11, no. 2, p. 87-94. ISSN 2299-8624. DOI 10.12913/22998624/69419

LEPOURAS, George, CHARITOS, Dimitrios, VASSILAKIS, Costas, CHARISSI, Anna, HALATSI, Leda (2001). Building a VR museum in a museum. In: Proc. 2001 V RIC Laval Virtual International Conference, 16-18 May 2001, Laval, France, p. 1-8. ISBN 5343545.

MILOSZ, Marek, MILOSZ, Elzbieta, MONTUSIEWICZ, Jerzy (2020). Determination of ceramic tile colour surface areas on the medieval Sher-Dor Madrasah mosaic in Samarkand - Problems and solutions. In: Digital Applications in Archaeology and Cultural Heritage, vol. 16, p. 1-6. ISSN 2212-0548. DOI 10.1016/j.daach.2020.e00134

MONTUSIEWICZ, Jerzy, BARSZCZ, Marcin, SKULIMOWSKI, Stanisław, KAYUMOV, Rahim, BUZRUKOV, Muhammad (2018). The concept of low-cost interactive and gamified virtual exposition. In: INTED2018 Proceedings, p. 353-363.

ORIFJONOVA, Gulra'no Ravshan (2019). Ethnographic collections of museums in Uzbekistan: samples of copper-embossing art. In: Muzeológia a kultúrne dedičstvo, vol. 7, no. 1, p. 235-240. ISSN 1339-2204.

POLUPANOW, S. N. (1948). Architekturnye Pamiatniki Samarkanda. Moscow: Uzdatelistwo Akademii Architektury CCCP.

PRIPORAS, Constantinos-Vasilios, STYLOS, Nikolaos, FOTIADIS, Anestis (2017). Generation Z consumers' expectations of interactions in smart retailing: A future agenda. In: Computers in Human Behavior, vol. 77, p. 374-381. ISSN 0747-5632. 
K. Żyła - J. Montusiewicz - S. Skulimowski - R. Kayumov: VR technologies...

RAKHMANOW, Abusapikhan (2008). Architectural Monuments of Samarkand in the Timurid Epoch. In: Proceedings of the Workshop on Conservation and Management of Timurid Architecture, 21 April-2 May 2008, Tashkent, Samarkand, Shakhrisyabz, Bukhara, Khiva, Mega Basim, p. 32-43. ISBN 978-9943-357-01-3.

REMONDINO, Fabio, MENNA, Fabio, KOUTSOUDIS, Anestis, CHAMZAS, Christos, ELHAKIM, Sabry (2013). Design and implement a reality-based 3D digitisation and modelling project. In: 2013 Digital Heritage International Congress (DigitalHeritage), p. 137-144. ISBN 9781479931699. DOI 10.1109/DigitalHeritage.2013.6743723

SANTOS, Filipe, FONSECA, Benjamim, MORGADO, Leonel, MARTINS, Paulo (2008). Children as Active Partners: Strategies for Collaboration in Spatial Tasks through Virtual Worlds. In: Sixth International Conference on Creating, Connecting and Collaborating through Computing (C5 2008), Poitiers, p. 73-76. ISBN 0-7695-3115-6. DOI 10.1109/C5.2008.25

SCROFANI, Luigi, RUGGIERO, Luca (2013). Museum networks in the Mediterranean area: Real and virtual opportunities. In: Journal of Cultural Heritage, vol. 14, no. 3, p. S75-S79. ISSN 1296-2074. DOI 10.1016/j.culher.2012.11.016

SKULIMOWSKI,Stanisław,BADUROWICZ,Marcin,BARSZCZ,Marcin,MONTUSIEWICZ, Jerzy (2019). Design and optimisation methods for interactive mobile VR visualisation. In: IOP Conference Series: Materials Science and Engineering, vol. 710, p. 1-10. ISSN 1757-8981.

SZABÓOVÁ, Nela (2018). Úspechy výšiviek z produkcie Spolku Izabella na medzinárodnom trhu. In: Mureológia a kulturne dedičstvo, vol. 6, no. 1, p. 95-103. ISSN 1339-2204.

TIŠLIAR, Pavol (2017). The Development of Informal Learning and Museum Pedagogy in Museums. In: European Journal of Contemporary Education, vol. 6, no. 3, p. 586-592. ISSN 23049650. DOI 10.13187/ ejced.2017.3.586

TSICHRITZIS, Dennis, GIBBS, Simon (1991). Virtual Museums and Virtual Realities. In: International Conference on Hypermedia and Interactivity in Museums, p. 14-16. ISBN 1-88562603-7.

UNESCO, International Institute for Central Asian Studies (2015). Silk Road Memory of the World. Documentary Heritage Inscribe on the UNESCO "Memory of the World" International Register. Mega Basim. ISBN 978-9943-11-083-0.

ŻYŁA, Kamil (2019). Attention Deficit Hyperactivity Disorder Detection - from Psychological Checklists to Mobile Solutions. In: Studies in Logic, Grammar and Rethoric, vol. 60, p. 85-100. ISSN 0860-150X. DOI 10.2478/slgr-2019-0047

ŽUPČÁN, Ladislav (2019). Platforma kultúrneho dedičstva v súčasnej kyberkultúre. In: Muzeológia a kultúrne dedičstvo, vol. 7, no. 1, p. 57-73. ISSN 1339-2204.

\section{Internet sources}

3D Digital Silk Road, accessed 22 January 2020, http:/ / silkroad3d.com/

3D-ICONSCaseStudies, accessed10March2020, https://www.slideshare.net/3dicons/3diconscase-studies-43942076

3D-ICONS Guidelines, accessed 10 March 2020, https:/ / www.slideshare.net/3dicons/3diconsguidelines

Cultural Heritage \& History 3D models | Categories - Sketchfab, accessed 10 March 2020, https://sketchfab.com/3d-models/categories/cultural-heritage-history

Newsletter of the Department of Computer Science, Lublin University of Technology, accessed 22 January 2020, https://cs.pollub.pl/news/?lang=en 
Europa Nostra, Work plan for culture 2019-2022, accessed 22 January 2020, https://www. europanostra.org/work-plan-for-culture-2019-2022-eu-ministers-of-culture-make-thelegacy-of-the-european-year-a-priority/

European Year of Cultural Heritage, accessed 22 January 2020, https://europa.eu/culturalheritage/european-year-cultural-heritage_en.html

Explore virtual reality at the National Museum of Singapore this weekend - CNA, accessed 10 March 2020, https://www.channelnewsasia.com/news/lifestyle/explore-virtual-reality-atthe-national-museum-of-singapore-this-9481696

Jupiter Hall VR tour development for State Hermitage Museum, accessed 10 March 2020, https://nntc.digital/blog/vr-and-ar/jupiter-hall-vr-tour-development-for-state-hermitagemuseum-/

Khiva360, accessed 10 March 2020, https://khiva360.nazzar.uz/

Modigliani VR: The Ochre Atelier - Behind the Scenes | Tate, accessed 10 March 2020, https://www.tate.org.uk/whats-on/tate-modern/exhibition/modigliani/modigliani-vrochre-atelier

UNDP, Social and Environmental Standards, Standard 4, accessed 22 January 2020, https:// info.undp.org/sites/bpps/SES_Toolkit/SitePages/Standard\%204.aspx 